\title{
Pictet-Spenglerases in Alkaloid Biosynthesis: Future Applications in Biocatalysis
}

\author{
Rebecca Roddan ${ }^{1,2}$, John M. Ward ${ }^{3}$, Nicholas H. Keep ${ }^{1}$ and Helen C. Hailes ${ }^{2 *}$ \\ ${ }^{1}$ Institute for Structural and Molecular Biology, Department of Biological Sciences, Birkbeck, \\ University of London, Malet Street, London, WC1E 8HX, U.K. \\ ${ }^{2}$ Department of Chemistry, University College London, 20 Gordon Street, London, WC1H \\ OAJ, U.K. \\ ${ }^{3}$ Department of Biochemical Engineering, University College London, Bernard Katz Building, \\ London, WC1E 6BT, U.K.
}

Corresponding author: Helen C. Hailes*, Department of Chemistry, University College London, 20 Gordon Street, London, WC1H 0AJ, U.K. (h.c.hailes@ucl.ac.uk)

\section{Abbreviations:}

THIQ, tetrahydroisoquinoline; NCS, norcoclaurine synthase; BIA, benzylisoquinoline alkaloid; Tf, Thalictrum flavum; Cj, Coptis japonica; NMR, nuclear magnetic resonance; DIS, deacetylipecoside synthase; DIIS, deacetylisoipecoside; STR, strictosidine synthase; MIA, monoterpenoid indole alkaloid, Rs, Rauvolfia serpentia; Cr, Catharanthus roseus. 


\begin{abstract}
Pictet-Spenglerases provide a key role in the biosynthesis of many biologically-active alkaloids. There is increasing use of these biocatalysts as an alternative to traditional organic synthetic methods as they provide stereoselective and regioselective control under mild conditions. Products from these enzymes also contain privileged drug scaffolds (such as tetrahydroisoquinoline or $\beta$-carboline moieties), so there is interest in the characterisation and use of these enzymes as versatile biocatalysts to synthesize analogues of the corresponding natural products for drug discovery. This review discusses all known PictetSpenglerase enzymes and their applications as biocatalysts.
\end{abstract}

\title{
1.1 Introduction
}

Alkaloids are a group of naturally-occurring, nitrogen-containing molecules, many of which are pharmacologically relevant. Some widely known examples are quinine (anti-malarial), berberine (anti-bacterial), ergotamine (childbirth) and morphine (analgesic) [1]. Alkaloids have been used for medicinal and recreational purposes for millennia and there continues to be significant interest in isolating novel bioactive compounds from plants. There is also research activity focussed on the enzymes involved in alkaloid biosynthesis to understand their mechanism of action and replicate syntheses in vitro or in vivo.

The Pictet-Spengler reaction involves an intermolecular cyclisation reaction between a $\beta$ arylethylamine and an aldehyde or ketone. Synthetic approaches include the use of an acid or inorganic phosphate catalyst and the reaction proceeds via the condensation of the two substrates to form an iminium ion via an aminol intermediate [2,3]. Intramolecular nucleophilic attack of the aromatic ring onto the iminium ion provides ring closure and generates a stereogenic centre in the product, thus providing a significant increase in product molecular complexity in a single step (Scheme 1).[4]

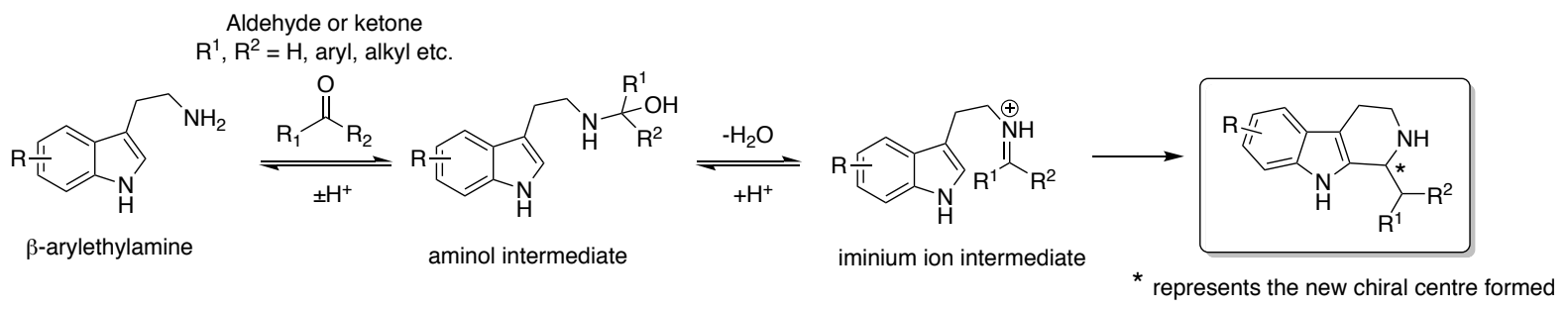

Scheme 1: The general scheme for the Pictet-Spengler reaction. A $\beta$-arylethylamine (e.g. an indole or aryl ring) is condensed with an aldehyde or ketone to give an iminion ion intermediate. An intramolecular cyclisation then occurs to give the product. A new chiral centre is formed in the product if $R^{1} \neq R^{2}$.

The Pictet-Spengler reaction is a key step in the biosynthesis of many alkaloids and a variety of Pictet-Spenglerases (also known as PSases) involved in alkaloid production have been characterised and used in the syntheses of pharmacologically relevant molecules.[5] PictetSpenglerases are classified as lyases (EC 4) but there is no subclass dedicated to them. This review article discusses current progress in the identification and characterisation of PictetSpenglerases and applications in the synthesis of alkaloids, with a view to highlighting future biocatalytic opportunities. 


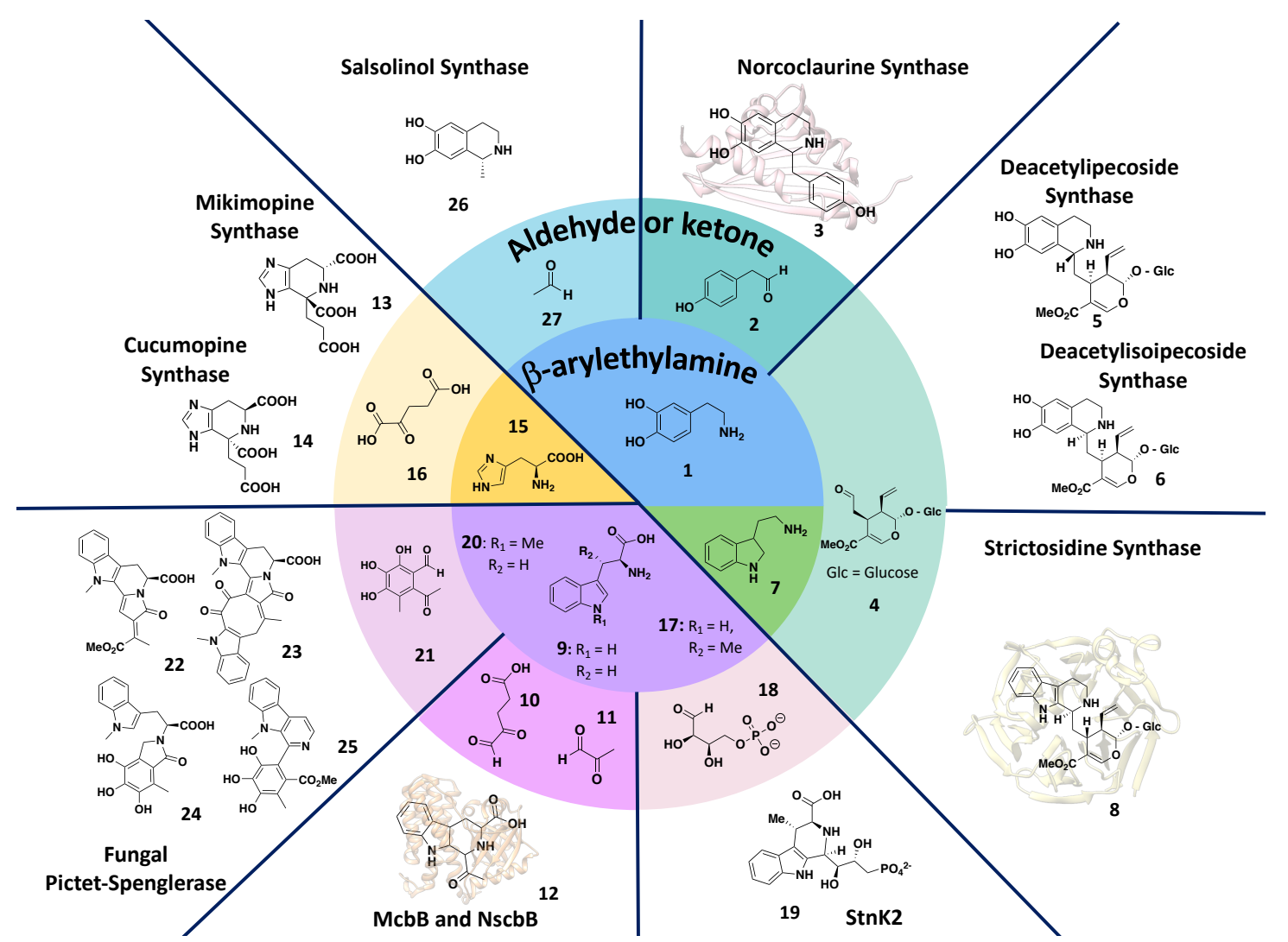

Figure 1: The natural substrate scope of known Pictet-Spenglerases. Each segment corresponds to an enzyme, which condenses a $\beta$-arylethylamine and an aldehyde or ketone to give the product. Protein structures, where known, are represented. The structures of NCS (PDB: 5N8Q), strictosidine synthase (PDB: 2FPC) and McbB (PDB: 3X27) are behind 3, 8 and 12.

\subsection{Plant Pictet-Spenglerases}

\subsubsection{Norcoclaurine synthase}

Norcoclaurine synthase (NCS) performs a stereoselective Pictet-Spengler reaction between two tyrosine-derived molecules, dopamine (1) and 4-hydroxyphenylacetaldehyde (2) to give (S)-norcoclaurine (3), the first committed intermediate to benzylisoquinoline alkaloids (BIAs) [6]. Many BIAs are pharmaceutically relevant and widely used, such as the analgesic, morphine and noscapine, used as an anti-tussive [7].

Two NCSs, isolated from Thalictrum flavum (TfNCS) and Coptis japonica (CjNCS) have been most widely characterised and early work on the enzymes isolated from plants established the native substrates and enzyme kinetics $[8,9]$. Since then recombinant enzymes have been generated in $E$. coli and a variety of structural studies have been performed with TfNCS. Initially a mechanism was proposed whereby the aldehyde binds first to the active site based upon NMR studies and a co-crystallised structure with a non-substrate benzaldehyde $[10,11]$. However, this did not account for the diverse aldehyde substrate scope observed and mechanistically an active site residue is required to deprotonate the catechol, for the intramolecular cyclisation with the iminium ion intermediate. More recent computational docking experiments and crystallographic studies, using a non-productive mimic of an advanced reaction intermediate co-crystallised with TfNCS (Figure 2a), provided new 
mechanistic insights. These suggested that dopamine binds first to the active site, followed by the aldehyde $[12,13]$. A subsequent crystal structure and molecular dynamics studies using novel aldehyde substrates, as well as a new computational study have further supported the 'dopamine first' mechanism [13,14]. This mechanism also accounts for the impressive substrate scope observed by TfNCS.
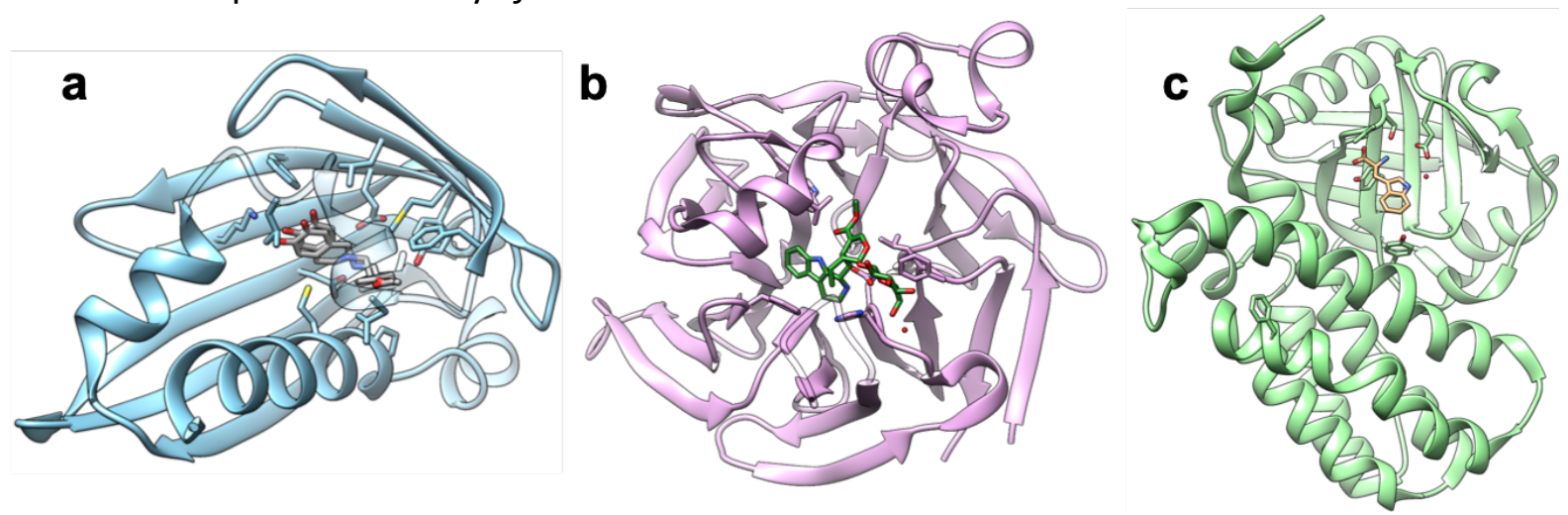

Figure 2: a) Co-crystallised structure of $T f N C S$ with an intermediate analogue in a productive and non-productive binding-mode (PDB: $5 N O N$, chain A). b) Co-crystallised structure of RsSTR with strictosidine (PDB: 2V91, chain A). c) Co-crystallised structure of McBb with Ltryptophan (PDB: $3 \times 27$, chain A). For structures key active site residues are represented.

Initial substrate screens showed that a variety of different aldehydes were accepted as substrates but that the amine substrate scope was narrower, with the meta-hydroxyl moiety of dopamine (1, figure 1 ) being essential for a productive reaction $[15,16]$. Moreover, when chiral $\alpha$-methyl substituted aldehydes were used, a kinetic resolution of the aldehyde occurred, resulting in the preferential acceptance of the $(R)$-aldehyde by TfNCS, giving $\left(1 S, 1^{\prime} R\right)$-tetrahydroisoquinoline (THIQ) products in high diastereomeric ratios (98:2) using an active site mutant M97V [17]. Remarkably, ketones have also been accepted as substrates, leading to the biocatalytic production of chiral 1,1'-disubstituted and spiro-THIQs [18]. Indeed, a variety of linear aliphatic aldehydes have been accepted and this has been exploited in chemoenzymatic cascades to produce trolline derivatives, $(S)$-benzylisoquinoline and $(S)$ tetrahydroprotoberberine alkaloids [19-21]. A summary of the reported NCS substrate scope is given in scheme 2. In vivo pathways incorporating NCS, to the alkaloids (S)-reticuline and thebaine have also been reported in E. coli and S. cerevisiae [22-25]. This in particular highlights the exciting opportunities of using NCS and variants in the preparation of a significant range of alkaloids.

The substrate scope of CjNCS2 (59\% identity, 78\% homology to TfNCS) has been explored less extensively. To date, it accepts a range of aldehydes as substrates but not ketones [18]. The key active site residues in TfNCS and CjNCS2 are mostly conserved, other than A(Cj)79I(Tf) and there is an extra alanine in this loop in CjNCS2. However, the variant A79I in TfNCS does not alter the ketone acceptance observed, suggesting that perhaps the extra alanine in the loop is responsible for the differing activities [18]. NCSs from other plants (such as Argemone mexicana, Papaver bracteatum and Corydalis saxicola) have also been expressed recombinantly, characterised and found to give THIQ products in high yield with high enantiomeric excesses in the products [26]. 
NCSs used in biocatalytic applications have been shown to produce tetrahydroisoquinolines with $(S)$-stereochemistry at the C-1 carbon. However, there have been reports of the isolation of $(R)$-norcoclaurine from the seed embryo of the sacred lotus plant, Nelumbo nucifera [2729]. This suggests that the NCS that can either perform an $(R)$-selective reaction or a norcoclaurine epimerase may be present [30-32]. Recently, seven different genes encoding for NCS have also been identified in the sacred lotus genome [33]. Further details are discussed in a comprehensive review on sacred lotus alkaloid biosynthesis [34].

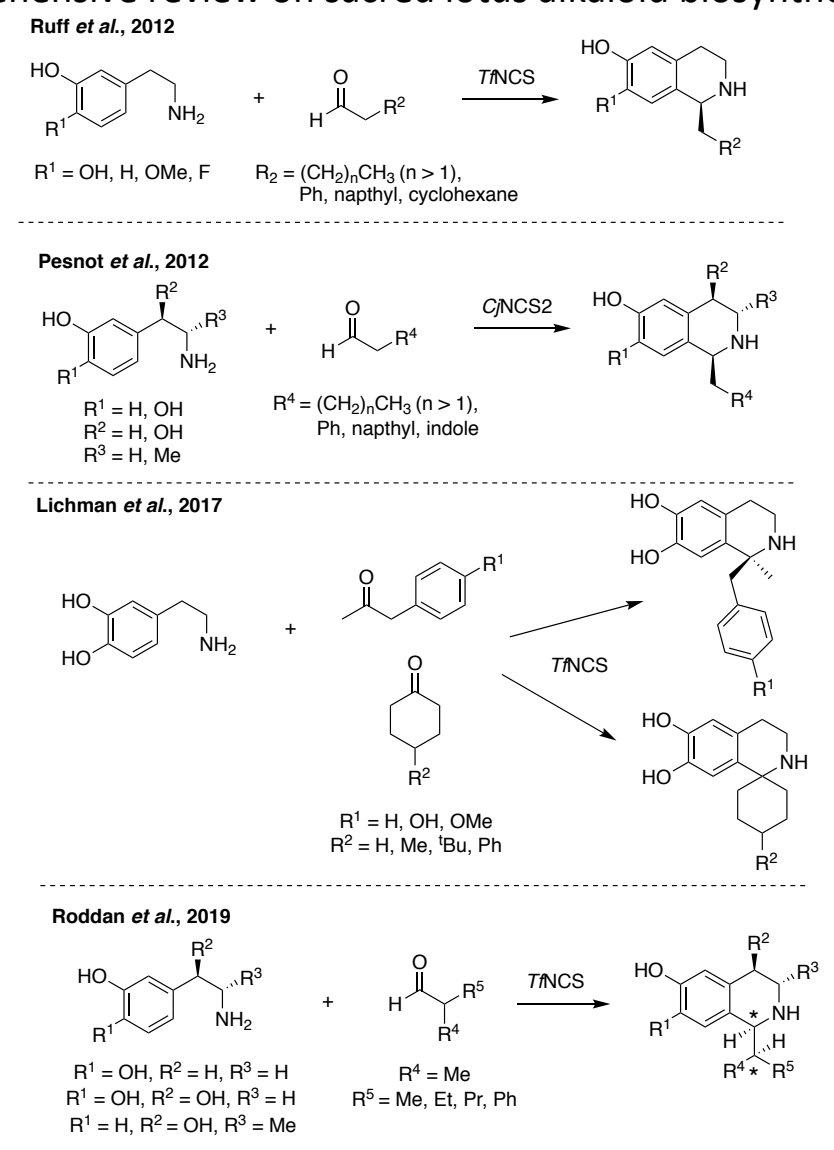

Scheme 2: Selected biocatalytic reactions with NCSs derived from Thalictrum flavum (TfNCS) and Coptis Japonica (CjNCS2).

\subsubsection{Deacetylipecoside synthase}

Two different Pictet-Spenglerases have been identified in Alangium lamarckii with the ability to condense dopamine (1) and secologanin (4), a glucosylated monoterpene. Deacetylipecoside synthase (DIS) forms the $(R)$-enantiomer at C-1 to give $\mathbf{5}$ while deacetylisoipecoside (DIIS) forms the (S)-enantiomer in 6. Both undergo spontaneous lactamization followed by subsequent enzymatic modifications to give alangiside and isoalangiside-type glucosides respectively. DIS has been successfully isolated and purified from A. lamarckii and found to be $30 \mathrm{kDa}$ in molecular weight however, DIIS was found to be too labile for purification [35].

\subsubsection{Strictosidine synthase}

Strictosidine synthase (STR) catalyses the Pictet-Spengler reaction between tryptamine (7) and secologanin (4) to form 3- $\alpha(S)$-strictosidine (8), which is the biosynthetic precursor to monoterpenoid indole alkaloids [36]. There are over 2,000 different monoterpenoid indole 
alkaloids (MIAs), many of which have important medicinal activities, such as quinine (antimalarial), camptothecin (anti-tumour agent) and ajmaline (anti-arrhythmic) [37]. Two STRs have been most extensively characterised, isolated from Rauvolfia serpentia (RsSTR) and Catharanthus roseus (CrSTR) [38,39].

The mechanism of action was elucidated by Maresh et al. in 2008 [40] A crystal structure of recombinant $R S S T R$ co-crystallised in the presence of secologanin and tryptamine was solved (PDB: 2V91). The structure of STR is unusual, being the first example of a $\beta$-propeller protein found in the plant kingdom (Figure 2b). Sequence homology to similar structures is low [39]. Mutagenesis identified the key active site residues as E309, Y151 and H307. Kinetic isotope effects and $\mathrm{pH}$ dependence of the reaction suggested that formation of the iminium ion intermediate is acid-catalysed and that the final deprotonation step is base-catalysed. $A b$ initio calculations have indicated that the reaction mechanism does not go via a spiroindolenine intermediate [40].

The amine donor substrate scope is not limited to tryptamine and screens have been performed with wild-type and mutated STR [41-43]. Analogues with hydroxyl and methoxy groups at C-5 and C-6 respectively of tryptamine were accepted [44]. Activity was also retained when the tryptamine benzene ring was substituted for a pyridine moiety or if the tryptamine pyrrole ring was exchanged for a furan ring [45]. The aldehyde substrate scope has also been altered using active site mutants $[43,44]$ and a recent review discusses the substrate scope in detail [46].

Despite these successes, recombinant expression and isolation of STRs has proven challenging. A recent paper by Pressnitz et al. improved the expression and activity of clarified cell lysates 100 -fold via optimisation of the expression protocol by using synthetic, codonoptimised genes in E. coli and the removal of signal peptides [47]. Interestingly, a variety of non-natural, aliphatic aldehydes have been accepted by four different STRs to give single enantiomer products with $(R)$-stereochemistry at the C-1 position. This led to the enantioselective chemoenzymatic synthesis of $(R)$-harmicine, in an analogous method to the synthesis of trolline-derivatives using TfNCS [47]. STR has also been employed in the stereoselective synthesis of $\mathrm{N}$-substituted strictosidine derivatives as novel topoisomerase inhibitors and other alkaloids via chemoenzymatic cascades $[42,48]$. These examples highlight its potential application in future biocatalytic reactions and cascades.

\subsubsection{Putative Pictet-Spenglerase from Lophocereus schottii}

THIQ alkaloids with an isobutyl group at C-1 (lophocereine) have been isolated from L. schotti, a desert cactus $[49,50]$. No other naturally-occurring THIQs with an aliphatic group at the $\mathrm{C}-1$ position have been identified. Feeding studies have suggested that both leucine and mevalonic acid are precursors to lophocereine. It is however known that leucine is not incorporated via mevalonic acid [51,52]. Although the enzymes present in L. schottii have not been identified, 3-methylbutanal was also incorporated during feeding studies suggesting that lophocerine may be formed by a Pictet-Spenglerase $[53,54]$.

\subsection{Bacterial Pictet-Spenglerases}

\subsubsection{McbB}


The enzyme McbB (isolated from Marinactinospora thermotolerans) has been found to perform the Pictet-Spengler reaction between L-tryptophan (9) and oxaloacetaldehyde (10). Subsequent oxidation and decarboxylation steps give a $\beta$-carboline scaffold, found in many pharmacologically active molecules including benzodiazepine inverse agonists $[55,56]$. The enzyme has been shown to accept the non-natural substrates, 5-methyl-DL-tryptophan, 7methyl-DL-tryptophan and smaller aldehydes such as methylglyoxal (11), formaldehyde, acetaldehyde, propanal and isobutyraldehyde instead of 10 . The co-crystallised structure of McbB with L-tryptophan was obtained by Mori et al. in 2015 (PDB: 3X27). The active site is formed by a homodimerization where each monomer adopts a slightly different conformation. The catalytically important active site residues have been determined and sitedirected mutagenesis resulted in the formation of various active mutants. Mutations of two bulky residues, $H 87 A$ and $\mathrm{R} 72 \mathrm{~A}$, located at the entrance of the active site, led to the acceptance of the unnatural aldehyde, phenylglyoxal and condensation with L-tryptophan [56].

\subsubsection{NscbB}

Using genome mining, a new Pictet-Spenglerase enzyme, NscB, was discovered (identified in Nocardiopsis synnemataformans, derived from a kidney transplant patient). This comprehensive bioinformatics analysis using $\mathrm{McbB}$ as a search gene identified homologues based on existing microbial genomic data. NscbB catalyses the Pictet-Spengler reaction between L-tryptophan (9) and methylglyoxal (11) to give 1-acetyl-3-carboxy- $\beta$-carboline (12) i.e. the same reaction as with McbB. Both enzymes have high sequence identity (66\%) and homology (80\%) with a conserved active site residue E97 suggesting that that both operate via similar reaction mechanisms. NscbB has $c a$. a 30 fold higher $\mathrm{k}_{c a t} / \mathrm{K}_{\mathrm{M}}$ than $\mathrm{McbB}$, but NscbB is less thermally stable [57].

\subsubsection{Mikimopine synthase and cucumopine synthase}

Mikimopine (13) and cucumopine (14) are opines, formed via the Pictet-Spengler condensation of histidine (15) and $\alpha$-ketoglutaric acid (16). Opines are found in plant tumours induced by the parasite, Agrobacterium. The T-DNA encoding for the enzymes responsible for opine biosynthesis are passed to the plant via horizontal gene transfer. Opines are then synthesised by the plant cells and provide carbon and nitrogen sources for the invading bacteria. There has been little characterisation of the two enzymes; however the genes encoding mikimopine synthase (mis) have been isolated from $A$. rhizogenes and both enzymes have been expressed recombinantly in $E$. coli and enzymatic activity confirmed [5860]. Interestingly, the carbonyl substrate is an $\alpha$-ketoacid, whereas other Pictet-Spenglerases typically have an aldehyde as the natural substrate.

\subsubsection{StnK2}

Stnk2 is a Pictet-Spenglerase involved in the biosynthesis of streptonigrin, an alkaloid antibiotic with antitumor activity and it has high sequence identity with McbB (41\%). The enzyme performs a stereospecific reaction between $(2 S, 3 S)$ - $\beta$-methyl-tryptophan (17) and Derythrose-4-phosphate (18), with the newly formed chiral centre $\mathbf{1 9}$ in the $(R)$-configuration. (S)-Stereochemistry at C-3 in tryptophan is essential for its reactivity. The aldehyde substrate scope is limited: methylglyoxal and ethyl glyoxalate were not accepted. Interestingly, several fluoro-substituted L-tryptophan analogues were accepted and improved affinity was observed with 5 - and 6-fluoro-(2S,3S)- $\beta$-methyl tryptophan compared to the natural 
substrate. This is therefore a promising strategy for generating fluorinated analogues of streptonigrin [61].

\subsubsection{Non-ribosomal peptide synthetase SfmC (NRPS)}

The NRPS SfmC module has been found to perform seven sequential reactions, including two Pictet-Spengler condensation in the biosynthesis of Saframycin C, an anti-tumour antibiotic with a THIQ scaffold [62]. A full discussion of the NRPS SfmC Pictet-Spenglerase reaction is given in a recent review article [63].

\subsection{Fungal Pictet- Spenglerases}

Comparative genetic analysis has been used to identify a silent Pictet-Spenglerase in the fishderived fungi, Chaetomonium globosum. It was found that 1-methyl-L-tryptophan (20) can upregulate the expression of the Pictet-Spenglerase which results in the condensation of 1methyl-L-tryptophan (20) with the aldehyde, flavipin (21). The product is then altered by other fungal enzymes to give a novel class of alkaloids the 'chaetoglines' (22-25) and pharmacological activities have been assessed [64]. Two have anti-bacterial activities and another acts as an inhibitor of acetylcholinesterase [65].

\subsection{Mammalian Pictet-Spenglerases}

\subsubsection{Salsolinol synthase}

Salsolinol (26) has gained significant interest due to links with Parkinson's disease and alcoholism [66]. It is a THIQ alkaloid, formed by the condensation of dopamine (1) and acetaldehyde (27). Higher levels of $(R)$-salsolinol (26) have been found in the human brain, than the $(S)$-enantiomer from chiral HPLC studies $[67,68]$, suggesting that salsolinol is formed enzymatically [69]. An enzyme, isolated from Rattus norveticus, has been overexpressed recombinantly in rat PC21 cells and expression correlated with an increased production of salsolinol. Chiral HPLC analysis of isolated salsolinol gave an enantiomeric excess of $20 \%$ ( $R$ isomer) [70].

\subsection{Conclusions}

Pictet-Spenglerases are valuable biocatalysts for synthetic applications that can perform the Pictet-Spengler reaction in a stereoselective and regioselective manner under mild reaction conditions. Several Pictet-Spenglerases have been documented in the literature, however only two (NCS and STR) have been widely characterized and used to synthesize a variety of novel alkaloids. The biocatalytic use of other Pictet-Spenglerases has been limited by a narrow substrate scope, challenging isolation methods or poor enzyme stability, however there is significant scope for further investigations. In time, genome mining and bioinformatics techniques are likely to reveal further novel enzymes. Enzyme engineering based upon ligandbound crystal structures and directed evolution methods are also likely to widen the substrate scope of the known Pictet-Spenglerases. Thus, the applications of recombinant PictetSpenglerases in vitro or in vivo will continue to expand to generate diverse portfolios of alkaloids.

\section{Acknowledgements}

This work was supported by a Birkbeck PhD studentship to R.R. 
Keywords

Biocatalysis, Pictet-Spengler, alkaloid, biosynthesis.

References

1. Amirkia V, Heinrich M: Alkaloids as drug leads - A predictive structural and biodiversity-based analysis. Phytochem Lett 2014, 10:98-103.

2. Pictet $A$, Spengler $T$ : Über die bildung von isochinolin-derivaten durch einwirkung von methylal auf phenyl-äthylamin, phenyl-alanin und tyrosin. Berichte der Dtsch Chem Gesellschaft 1911, 44:2030-2036.

3. Pesnot T, Gershater MC, Ward JM, Hailes HC: Phosphate mediated biomimetic synthesis of tetrahydroisoquinoline alkaloids. Chem Commun 2011, 47:3242-3244.

4. Lin C-I, McCarty RM, Liu H: The Enzymology of Organic Transformations: A survey of named reactions in biological systems. Angew Chem Int Ed Engl 2017, 56:3446-3489.

5. Stöckigt J, Antonchick AP, Wu F, Waldmann H: The Pictet-Spengler reaction in nature and in organic chemistry. Angew Chemie - Int Ed 2011, 50:8538-8564.

6. Samanani N, Facchini PJ: Purification and characterization of norcoclaurine synthase the first committed intermediate in benzylisoquinoline alkaloid biosynthesis in plants. J Biol Chem 2002, 277:33878-33883.

7. Loder RE: Safe reduction of the cough reflex with noscapine A preliminary communication on a new use for an old drug. Anaesthesia 1969, 24:355-358.

8. Samanani N, Liscombe DK, Facchini PJ: Molecular cloning and characterization of norcoclaurine synthase, an enzyme catalyzing the first committed step in benzylisoquinoline alkaloid biosynthesis. Plant J 2004, 40:302-313.

9. Samanani N, Facchini PJ: Isolation and partial characterization of norcoclaurine synthase, the first committed step in benzylisoquinoline alkaloid biosynthesis, from opium poppy. Planta 2001, 213:898-906.

10. Berkner H, Schweimer K, Matecko I, Osch P: Conformation, catalytic site, and enzymatic mechanism of the PR10 allergen-related enzyme norcoclaurine synthase. Biochem J 2008, 413:281-290.

11. Ilari A, Franceschini S, Bonamore A, Arenghi F, Botta B, Macone A, Pasquo A, Bellucci $L$, Boffi A: Structural basis of enzymatic (S)-norcoclaurine biosynthesis. J Biol Chem 2009, 284:897-904.

12. Lichman BR, Gershater MC, Lamming ED, Pesnot T, Sula A, Keep NH, Hailes HC, Ward $J M$, Ward CJM: "Dopamine-first" mechanism enables the rational engineering of the norcoclaurine synthase aldehyde activity profile. FEBS J 2015, 282:1137-1151.

**13. Lichman BR, Sula A, Pesnot T, Hailes HC, Ward JM, Keep NH: Structural evidence for the dopamine-first mechanism of norcoclaurine synthase. Biochemistry 2017, 56:5274-5277.

A co-crystallized structure of NCS with an intermediate analogue confirms the dopamine-first mechanism of action and mechanistically relevant active site residues are identified.

**14. Sheng X, Himo F: Enzymatic Pictet-Spengler reaction: Computational study of the mechanism and enantioselectivity of norcoclaurine synthase. J Am Chem Soc 2019, 141:11230-11238.

This paper describes density functional theory calculations on NCS to investigate the reaction mechanism and the observed enantioselectivity. The 'dopamine-first' mechanism is confirmed and the stereoselectivity of the reaction is reproduced in 
calculations and rationalized.

15. Ruff BM, Bräse S, O'Connor SE: Biocatalytic production of tetrahydroisoquinolines. Tetrahedron Lett 2012, 53:1071-1074.

16. Nishihachijo M, Hirai Y, Kawano S, Nishiyama A, Minami H, Katayama T, Yasohara $Y$, Sato $\mathrm{F}$, Kumagai $\mathrm{H}$ : Asymmetric synthesis of tetrahydroisoquinolines by enzymatic Pictet-Spengler reaction. Biosci Biotechnol Biochem 2014, 78:701-707.

17. Roddan R, Gygli G, Sula A, Méndez-Sánchez D, Pleiss J, Ward JM, Keep NH, Hailes HC: Acceptance and kinetic resolution of $\alpha$-methyl-substituted aldehydes by norcoclaurine synthases. ACS Catal 2019, 9:9640-9649.

**18. Lichman BR, Zhao J, Hailes HC, Ward JM: Enzyme catalysed Pictet-Spengler formation of chiral 1,1'-disubstituted-and spiro-tetrahydroisoquinolines. Nat Commun 2017, 8:14883.

In this paper, the authors describe the acceptance of ketones as NCS substrates. This leads to the production of chiral 1,1'-disubstituted- and spirotetrahydroisoquinolines. These structures are present in many biologically active molecules, but chemical syntheses are challenging.

19. Zhao J, Lichman BR, Ward JM, Hailes HC: One-pot chemoenzymatic synthesis of trolline and tetrahydroisoquinoline analogues. Chem Commun 2018, 54:1323-1326.

20. Lichman BR, Lamming ED, Pesnot T, Smith JM, Hailes HC, Ward JM: One-pot triangular chemoenzymatic cascades for the syntheses of chiral alkaloids from dopamine. Green Chem 2015, 17:852-855.

*21. Wang Y, Tappertzhofen N, Méndez-Sánchez D, Bawn M, Lyu B, Ward J, Hailes HC: Design and use of de novo cascades for new benzylisoquinoline alkaloid biosynthesis. Angew Chemie Int Ed 2019, 131:1-7.

Tyrosinases and decarboxylases, combined with a transaminase enzyme and NCS are used for the chiral syntheses of a variety of natural and novel BIAs. Reactions are performed in vitro, thus avoiding a background, phosphate-mediated Pictet-Spengler reaction, leading to high enantiopurity in the products.

22. Nakagawa A, Minami H, Kim JS, Koyanagi T, Katayama T, Sato F, Kumagai H: A bacterial platform for fermentative production of plant alkaloids. Nat Commun 2011, 2:1-9.

23. Kim J-S, Nakagawa A, Yamazaki Y, Matsumura E, Koyanagi T, Minami H, Katayama T, Sato $F$, Kumagai $H$ : Improvement of reticuline productivity from dopamine by using engineered Escherichia coli. Biosci Biotechnol Biochem 2013, 77:2166-2168.

24. Galanie S, Thodey K, Trenchard IJ, Interrante MF, Smolke CD: Complete biosynthesis of opioids in yeast. Science (80- ) 2015, 349:1095-1100.

25. Trenchard IJ, Siddiqui MS, Thodey K, Smolke CD: De novo production of the key branch point benzylisoquinoline alkaloid reticuline in yeast. 2015 , doi:10.1016/j.ymben.2015.06.010.

26. Lechner H, Soriano P, Poschner R, Hailes HC, Ward JM, Kroutil W: Library of norcoclaurine synthases and their immobilization for biocatalytic transformations. Biotechnol J 2018, 13:1-9.

27. Hong $H$, Lee $Y-I$, Jin D: Determination of $\boldsymbol{R}-(+)$-higenamine enantiomer in Nelumbo nucifera by high-performance liquid chromatography with a fluorescent chiral tagging reagent. Microchem J 2010, 96:374-379.

28. Nishibe S, Tsukamoto H, Kinoshita H, Kitagawa S, Sakushima A: Alkaloids from embryo of the seed of Nelumbo nucifera. J Nat Prod 1986, 49:547-548. 
29. Koshiyama H, Ohkuma H, Kawaguchi H, Hsu H-Y, Chen Y-P: Isolation of 1-(phydroxybenzyl)-6,7-dihydroxy-1,2,3,4-tetrahydroisoquinoline(demethylcoclaurine), an active alkaloid from Nelumbo nucifera. Chem Pharm Bull 1970, 18:2564-2568.

30. Kashiwada Y, Aoshima A, Ikeshiro Y, Chen Y-P, Furukawa H, Itoigawa M, Fujioka T, Mihashi K, Cosentino LM, Morris-Natschke SL, et al.: Anti-HIV benzylisoquinoline alkaloids and flavonoids from the leaves of Nelumbo nucifera, and structureactivity correlations with related alkaloids. 2004, 13:443-448.

31. Lin Z, Yang R, Guan Z, Chen A, Li W: Ultra-performance LC separation and quadrupole time-of-flight MS identification of major alkaloids in plumula nelumbinis. Phytochem Anal 2014, 25:485-494.

32. Do TCMV, Nguyen TD, Tran H, Stuppner H, Ganzera M: Analysis of alkaloids in Lotus (Nelumbo nucifera Gaertn.) leaves by non-aqueous capillary electrophoresis using ultraviolet and mass spectrometric detection. J Chromatogr A 2013, 1302:174-180.

33. Li J, Lee E-J, Chang L, Facchini PJ: Genes encoding norcoclaurine synthase occur as tandem fusions in the Papaveraceae. Sci Rep 2016, 6:39256.

34. Menéndez-Perdomo IM, Facchini PJ: Benzylisoquinoline alkaloids biosynthesis in sacred lotus. Molecules 2018, 23:2899-2916.

35. De-Eknamkul W, Suttipanta N, Kutchan TM: Purification and characterization of deacetylipecoside synthase from. Phytochemistry 2000, 55:177-181.

36. Kishimoto S, Sato M, Tsunematsu Y, Watanabe K: Evaluation of biosynthetic pathway and engineered biosynthesis of alkaloids. Molecules 2016, 21:1078-1096.

37. O'Connor SE, Maresh JJ: Chemistry and biology of monoterpene indole alkaloid biosynthesis. Nat Prod Rep 2006, 23:532-547.

38. Brown S, Clastre M, Courdavault V, O'Connor SE: De novo production of the plantderived alkaloid strictosidine in yeast. PNAS 2015, 112:3205-3210.

39. Ma X, Panjikar S, Koepke J, Loris E, Stöckigt J: The structure of Rauvolfia serpentina strictosidine synthase Is a novel six-bladed-propeller fold in plant proteins. Plant Cell Online 2006, 18:907-920.

40. Maresh JJ, Giddings L-A, Friedrich A, Loris EA, Panjikar S, Trout BL, Stöckigt J, Peters B, $\mathrm{O}^{\prime}$ Connor SE: Strictosidine synthase: Mechanism of a Pictet-Spengler catalyzing enzyme. J Am Chem Soc 2008, 130:710-723.

41. Fischereder E, Pressnitz D, Kroutil W, Lutz S: Engineering strictosidine synthase: Rational design of a small, focused circular permutation library of the $\beta$-propeller fold enzyme. Bioorganic Med Chem 2014, 22:5633-5637.

42. Wu F, Zhu H, Sun L, Rajendran C, Wang M, Ren X, Panjikar S, Cherkasov A, Zou H, Stö $\mathrm{J}$ : Scaffold tailoring by a newly detected Pictet-Spenglerase activity of strictosidine synthase: From the common tryptoline skeleton to the rare piperazino-indole framework. J Am Chem Soc 2011, 134:1498-1500.

43. Chen S, Galan MC, Coltharp C, O'Connor SE: Redesign of a central enzyme in alkaloid biosynthesis. Chem Biol 2006, 13:1137-1141.

44. Loris EA, Panjikar S, Ruppert M, Barleben L, Unger M, Schübel H, Stöckigt J: Structurebased engineering of strictosidine synthase: auxiliary for alkaloid libraries. Chem Biol 2007, 14:979-985.

45. McCoy E, Galan MC, O'Connor SE: Substrate specificity of strictosidine synthase. Bioorg Med Chem Lett 2006, 16:2475-2478.

46. Zhu H, Kerčmar P, Wu F, Rajendran C, Sun L, Wang M, Stöckigt J: Using strictosidine synthase to prepare novel alkaloids. Curr Med Chem 2015, 22:1880-1888. 
**47. Pressnitz D, Fischereder E, Pletz J, Kofler C, Hammerer L, Hiebler K, Lechner H, Richter $\mathrm{N}$, Eger $\mathrm{E}$, Kroutil W: Asymmetric synthesis of (R)-1-alkyl substituted tetrahydro-ßcarbolines catalyzed by strictosidine synthases. Angew Chem Int Ed 2018, 57:1-6. Four recombinantly expressed STRs were shown to accept a range of low molecular weight, aliphatic aldehydes, leading to $(R)$-configured products in high enantiomeric excess (>98\%). Optically pure $(R)$-harmicine was produced in high yield using a chemoenzymatic cascade.

48. Cai Y, Zhu H, Alperstein Z, Yu W, Cherkasov A, Zou H: Strictosidine synthase triggered enantioselective synthesis of $\mathrm{N}$-substituted $(S)-3,14,18,19$-tetrahydroangustines as novel topoisomerase I inhibitors. ACS Chem Biol 2017, 12:3086-3092.

49. Arias S, Terrazas T, Cameron K: Phylogenetic analysis of Pachycereus (Cactaceae, Pachycereeae) based on chloroplast and nuclear DNA sequences. Syst Bot 2003, 28:547-557.

50. Djerassi C, Krakower GW, Lemin AJ, Liang HL, Mills JS, Villotti R: The neutral constituents of the cactus Lophocereus schottii. The Structure of lophenol-4 $\alpha-$ methyl- $\Delta$ 7-cholesten-3 $\beta$-ol - A Link in sterol biogenesis. 1958, 80:6284-6292.

51. O'Donovan DG, Horan H: The biosynthesis of lophocerine. J Chem Soc C Org 1968,

52. O'Donovan DG, Barry E: Biosynthesis of lophocerine in Lophocerus schottii. Part II. J Chem Sci Perkin I 1974,

53. Seigler DS: Plant Secondary Metabolism. Kluwer Academic Publishers; 1998.

54. Geissman TA, Crout DHG: Organic Chemistry of Secondary Plant Metabolism. Freeman, Cooper \& Company; 1969.

55. Evans AK, Lowry CA: Pharmacology of the beta-carboline FG-7142, a partial inverse agonist at the benzodiazepine allosteric site of the GABA(A) receptor: Neurochemical, neurophysiological, and behavioral effects. CNS Drug Rev 2007, 13:475-501.

56. Mori T, Hoshino S, Sahashi S, Matsui T, Morita H, Abe I: Structural basis for $\boldsymbol{\beta}$ carboline alkaloid production by the microbial homodimeric enzyme McbB. Chem Biol 2015, 22:898-906.

*57. Chen $Q$, Zhang S, Xie Y: Characterization of a new microbial Pictet-Spenglerase NscbB affording the $\beta$-carboline skeletons from Nocardiopsis synnemataformans DSM 44143. J Biotechnol 2018, 281:137-143.

A novel Pictet-Spenglerase was identified, capable of forming a tetrahydro- $\beta$ carboline scaffold. This Pictet-Spenglerase is involved in the biosynthesis of the antitumor agent, streptonigrin and is capable of accepting fluorinated derivatives of tryptophan, thus leading to the production of fluorinated streptonigrin analogues.

58. Brevet J, Borowski D, Tempe J: Identification of the region encoding opine synthesis and of a region involved in hairy root induction on the T-DNA of cucumber-type Ri plasmid. Mol Plant-Microbe Interact 1988, 1:75-70.

59. Suzuki K, Tanaka N, Kamada H, Yamashita I: Mikimopine synthase (mis) gene on pRi1724. Gene 2001, 263:49-58.

60. Kovacova V, Zluvova J, Janousek B, Talianova M, Vyskot B: The evolutionary fate of the horizontally transferred agrobacterial mikimopine synthase gene in the genera Nicotiana and Linaria. PLoS One 2014, 9:1-23.

61. Wang $X$, Kong D, Huang $T$, Deng $Z$, Lin S: StnK2 catalysing a Pictet-Spengler reaction involved in the biosynthesis of the antitumor reagent streptonigrin. Org Biomol Chem 2018, 16:9124-9128. 
62. Koketsu K, Watanabe $\mathrm{K}$, Suda $\mathrm{H}$, Oguri $\mathrm{H}$, Oikawa $\mathrm{H}$ : Reconstruction of the saframycin core scaffold defines dual Pictet-Spengler mechanisms. Nat Chem Biol 2010, 6:408410.

63. Koketsu K, Minami A, Watanabe K, Oguri H, Oikawa K: Pictet-Spenglerase involved in tetrahydroisoquinoline antibiotic biosynthesis. Curr Opin Chem Biol 2012, 16:142149.

64. Yan W, Ge HM, Wang G, Jiang N, Mei YN, Jiang R, Li SJ, Chen CJ, Jiao RH, Xu Q, et al.: Pictet-Spengler reaction-based biosynthetic machinery in fungi. PNAS 2014, 111:18138-18143.

65. García-Ayllón M-S, Small DH, Avila J, Sáez-Valero J, Tsim K: Revisiting the role of acetylcholinesterase in Alzheimer's disease: cross-talk with P-tau and $\boldsymbol{\beta}$-amyloid. Front Mol Neurosci 2011, 4:1-9.

66. Kurnik-Łucka M, Panula P, Bugajski A, Gil K: Salsolinol: an unintelligible and doublefaced molecule-lessons learned from in vivo and in vitro experiments. Neurotox Res 2018, 33:485-514.

67. Deng $Y$, Maruyama W, Dostert $P$, Takahashi T, Kawai M, Naoi E' M: Determination of the (R)-and (S)-enantiomers of salsolinol and $\mathrm{N}$-methylsalsolinol by use of a chiral high-performance liquid chromatographic column. J Chromatogr B 1995, 670:47-54.

68. Naoi M, Maruyama W, Dostert $P$, Kohda K, Kaiya T: A novel enzyme enantioselectively synthesizes $(\mathrm{R})$ salsolinol, a precursor of a dopaminergic neurotoxin, $\mathrm{N}$ methyl(R)salsolinol. Neurosci Lett 1996, 212:183-186.

69. Chen X, Arshad A, Qing H, Wang R, Lu J, Deng Y: Enzymatic condensation of dopamine and acetaldehyde: a salsolinol synthase from rat brain. Biologia (Bratisl) 2011, 66:1183-1188.

70. Chen X, Zheng X, Ali S, Guo M, Zhong R, Chen Z, Zhang Y, Qing H, Deng Y: Isolation and sequencing of salsolinol synthase, an enzyme catalyzing salsolinol biosynthesis. ACS Chem Neurosci 2018, 9:1388-1398. 